\title{
A Study of Vehicle Fuel Consumption Simulation using VHDL-AMS Multi-domain Simulation
}

\author{
Takashi Abe*, Shikoh Takakura* and Tsuyoshi Higuchi*
}

\begin{abstract}
The vehicle system is a multi-domain system that requires many branches of science and engineering. Therefore the development of the vehicle system requires the use of design methodologies that utilize simulations, which have grown increasingly sophisticated in recent years. Our research group proposed a simulation modeling method based on the VHDL-AMS language. This paper describes how VHDL-AMS is used to model of vehicle fuel consumption simulation. The fuel consumption is shown using proposed simulation model on the Japanese 10-15 mode. We examine the influence of the vehicle system with electrical load and hill climb resistance in the vehicle running resistance.
\end{abstract}

Keywords: Vehicle, Fuel consumption, System simulation, Multi-domain simulation

\section{Introduction}

The setting of a stricter carbon dioxide emissions reduction target due to global warming has led to several discussions on enviroment-responsive system car. Air pollution in major urban centers is also an extremely important environmental issue, and the need to reduce traffic accidents and increase safety, are further considerations related to the use of vehicles [1]. To meet these demands, technologies related to vehicle development have continued to increase in complexity in recent years. Then, the usage of simulation technology in the design and development phase has become increasingly indispensable [2]. The vehicle system is a multi-domain system that requires many branches of science and engineering, such as mechanical, heat, magnetic, hydraulic and electrochemical fields, as well as the electrical circuits and control circuits that drive them. Therefore, we considered modeling using VHDL-AMS (Very High Speed Integrated Circuit Hardware Description Language-Analog and Mixed Signal) [3]. The VHDL-AMS is a general-purpose circuit description language, which has the possibility of applying Kirchhoff's law to the multi-domain energy simulation using the same topology of electrical circuits. And so, we proposed a vehicle system simulation, and reported various analysis results [4]-[7].

This paper describes how VHDL-AMS is used to model a vehicle fuel simulation. We describe the calculation model of the amount of fuel supply and fuel consumption

\footnotetext{
* Division of Electrical Engineering and Computer Science, Graduate School of Engineering Nagasaki University, Japan. (abet@nagasakiu.ac.jp)
}

Received 15 April 2013 ; Accepted 30 April 2013 by using the VHDL-AMS. The fuel consumption results are shown in consideration of the power-network system comprised of the alternator, battery and electrical load. In addition, we examine the influence of hill climb resistance in the vehicle running resistance.

\section{Multi-Domain Simulation}

To discuss the optimization of a whole vehicle, as discussed before, we should consider multi-domain energy at the same time and an effective integrative simulation tool that takes amount of these energies. Previously, the analysis of simulation was focusing on the development of each vehicle components. This means that the purpose of simulation was the optimization of each component. However for the past-mentioned reasons, to optimize whole vehicle system and exhausted carbon dioxide, the technology that can consider whole vehicle energy is needed. For that purpose, it is necessary to develop a simulation model, which can consider the behavior of energy conservation law in multi-domains simultaneously. By this development, it is possible to discuss the interaction with different technical fields. Physics in vehicle can be mostly discussed by analogue derivation. The analogue derivation can be expressed by through quantity and across quantity. Here, for example of the electrical domain, the through quantity and across quantity means current and voltage respectively. Figure 1 shows the notion of through quantity and across quantity in the Kirchhoff's law. The law is also energy conservation law. The Table 1 shows the application of the Kirchhoff's law to other technical domain [3]. The IEEE 1076.1 adopts the law. Therefore we decided 
that IEEE 1076.1 (VHDL-AMS) is the most effective technique during the study of whole vehicle modeling[4][7].

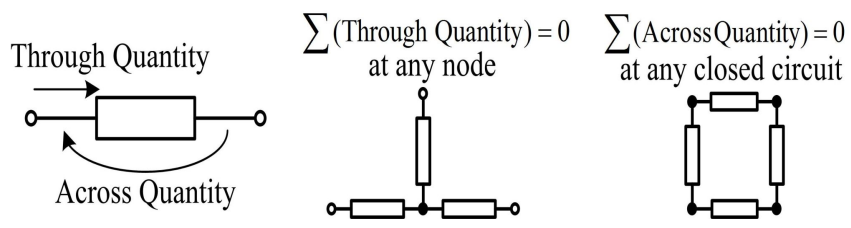

Fig. 1. The notion of Kirchhoff's law

Table 1. Multi-domain Physics

\begin{tabular}{|l|c|c|c|}
\hline & Electrical & Translational_V & Rotational_V \\
\hline Across & Voltage & Velocity & Angular \\
quantity & $(\mathrm{V})$ & $(\mathrm{m} / \mathrm{s})$ & velocity (rad/s) \\
\hline Through & Current & Force & Torque \\
quantity & (A) & $(\mathrm{N})$ & $(\mathrm{Nm})$ \\
\hline
\end{tabular}

\section{Modeling of Vehicle System}

\subsection{Model for Calculating the fuel consumption}

The engine rotational speed is calculated using the vehicle running speed as the input. Equation (1) is used for the calculation.

$$
N_{e}=\frac{1000}{120 \pi} \cdot \frac{i_{m} \cdot i_{f}}{r} \cdot V
$$

Where, $N_{e}$ is the engine rotational speed $[\mathrm{r} / \mathrm{min}], V$ is the vehicle running speed $[\mathrm{km} / \mathrm{h}], r$ is the effective tire radius of the drive wheel $[\mathrm{m}], i_{m}$ is the gear ratio, and $i_{f}$ is the final reduction gear ratio, respectively.

The engine torque $T$ is calculated using the vehicle running resistance as following equation (2), (3).

Case of $R \geq 0$

$$
T=\frac{r}{\eta_{m} \eta_{f} i_{m} i_{f}} \cdot R
$$

Case of $R<0$

$$
T=\frac{r \cdot \eta_{m} \eta_{f}}{i_{m} i_{f}} \cdot R
$$

Where, $T$ is the engine torque $[\mathrm{Nm}], \eta_{m}$ is the power transmission efficiency of the transmission, $\eta_{f}$ is the power transmission efficiency of the Differential Gear.

Also, a running resistance is generated which decreases a vehicle driving force. The running resistance $R$ has the rolling resistance $R_{r}$, the air resistance $R_{a}$, the hill climb resistance $R_{g}$ and the acceleration resistance $R_{i}$. These are represented by the following equation.

$$
\begin{aligned}
R & =R_{r}+R_{a}+R_{g}+R_{i} \\
& =\mu_{r} M g+\kappa v^{2}+M g \sin \theta+\left(M+M_{r}\right) \alpha
\end{aligned}
$$

Where, $R$ is the vehicle running resistance $[\mathrm{N}], \mu_{r}$ is the rolling resistance coefficient, $\kappa$ is the air resistance coefficient, $\theta$ is the slope angle, $M$ is the vehicle weight $[\mathrm{kg}], M_{r}$ is the equivalent weight of rotating parts [kg], $\alpha$ is the vehicle acceleration $[\mathrm{m} / \mathrm{s} / \mathrm{s}], g$ is the gravitational acceleration, respectively.

Equation of motion is represented by the relationship between the vehicle running resistance and the driving force, as in equation (5).

$$
F=\mu_{r} M g+\kappa v^{2}+M g \sin \theta+\left(M+M_{r}\right) \alpha
$$

Also, engine power is calculated using equation (6).

$$
P=\frac{2 \pi N_{e} T}{60}
$$

The fuel consumption $f_{t}[\mathrm{~g} / \mathrm{s}]$ is calculated using general fuel consumption contour line as shown Fig.2, and using the relationship between the engine rotational speed, equation (1), and the engine torque, equation (2)(3). The relationship between the fuel consumption ratio $f[\mathrm{~g} / \mathrm{kWh}]$ and the fuel consumption $f_{t}$ is represented using the engine power as in equation (7).

$$
f_{t}=\frac{f \cdot P}{3.6 \times 10^{6}}
$$

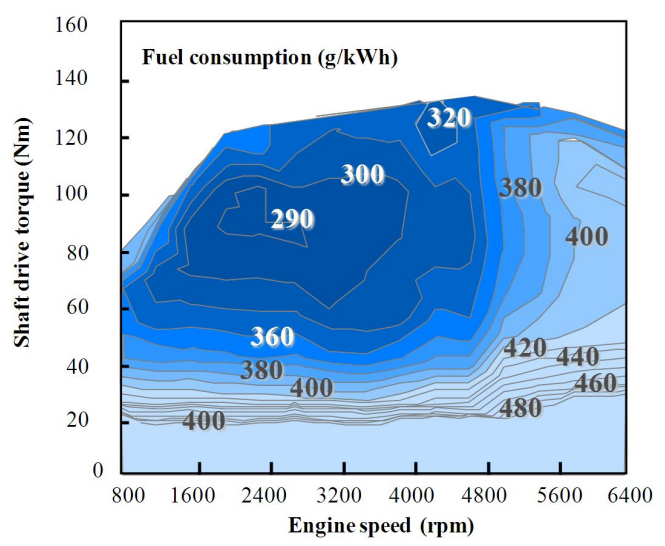

Fig. 2. Fuel Consumption Map 


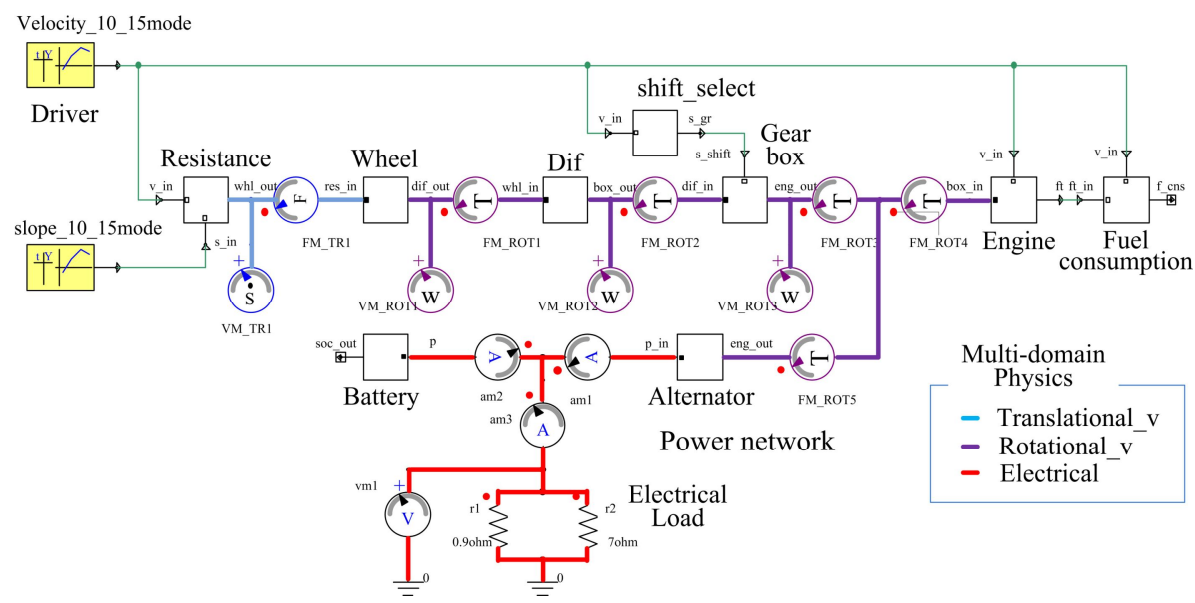

Fig. 3. Simulation Model

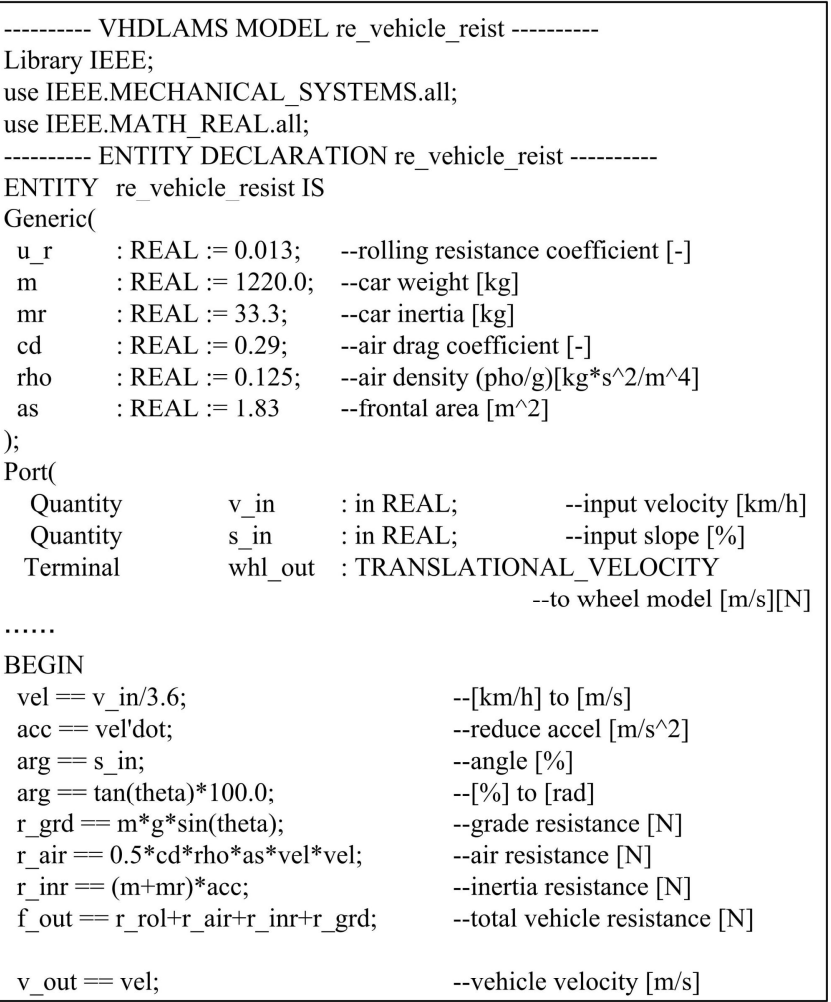

Fig. 4. Vehicle Running Resistance Model

\subsection{Description of Models}

The whole simulation model for fuel consumption calculation is shown Fig. 3. This model consists of the driver, engine, transmission (differential gear, gear box), wheels, shift select, running resistance and power-network. The driving pattern is used the Japanese 10-15 mode as the driver model. Three domains, Electrical, Translational_V and Rotational_V, are mixed in the whole simulation model. The constitution and description using VHDL-AMS for each model element are discussed below.

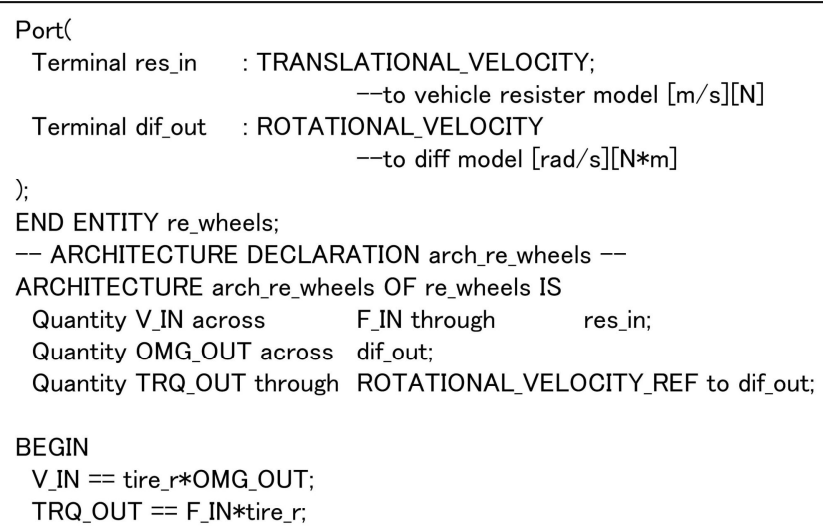

Fig. 5. Wheel Model

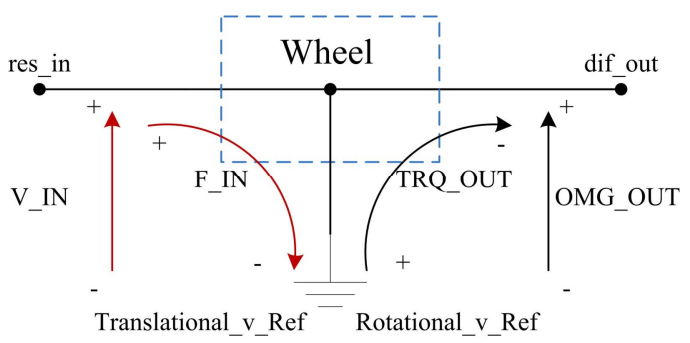

Fig. 6. Wheel Model

(1) The Vehicle Running Resistance Modeling

This model is described as vehicle model with motion equation. In this model, the driving force is derived from the rolling resistance, the acceleration resistance, the air resistance and the hill climb resistance. The vehicle velocity also is derived. The part of the description of this model using VHDL-AMS is shown in Fig. 4.

(2) The Wheel Modeling

This model exchanges the Translational_V domain of the resistance model for the rotational_V domain of the differential model, as shown Fig.5 and Fig.6. Those 
relations, velocity and angular velocity, force and torque, are calculated the radius of the tire.

\section{(3) Differential Gear Modeling}

The part of the description of the differential gear model by VHDL-AMS is shown in Fig.7. The relations of input and output are defined by the efficiency (eta) and the ratio (ratio) of differential gear in this model. The rotational_V domain is used in this model.

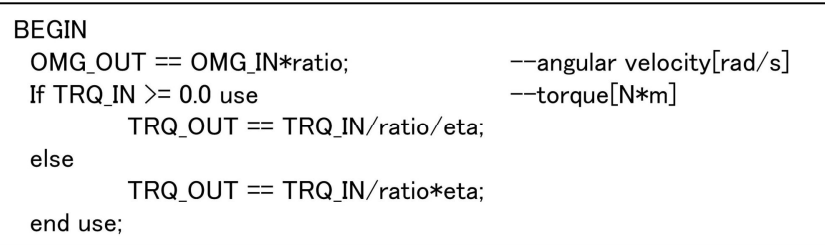

Fig. 7. Differential Gear Model

\section{(4) Gear Box Modeling}

The efficiency and the ratio of transmission gear are defined in this model. And also the torque and the speed for engine are derived in this model. The part of the description of the gear box model by VHDL-AMS is shown in Fig. 8 . The gear ratio is selected by shift position depending on the driving pattern.

\section{(5) Engine Map Modeling}

The engine map model is described using fuel consumption contour line as shown Fig.2. The fuel consumption rate is derived from the relationship of the engine speed and the engine torque. The part of the description of the gear box model by VHDL-AMS is shown in Fig. 9.

\section{(6) Fuel Consumption Calculation Modeling}

This model calculates the fuel consumption from fuel supply and the mileage, as shown in Fig. 10.

\section{(7) Alternator Modeling}

This model exchanges the rotational_V domain of the engine and gear model for the electrical domain of the battery model, as shown in Fig. 11 and 12. The alternator is a claw-pole field type synchronous generator with field winding and a three-phase full-wave rectifier circuit. The modeling of the alternator can be described using the voltage and motion equation. But for the purpose of simplification, It is possible to model by using a look-up table from experimental or analysis result data. In this case, the experimental current vs. speed table is used in this model as shown in Fig. 13.

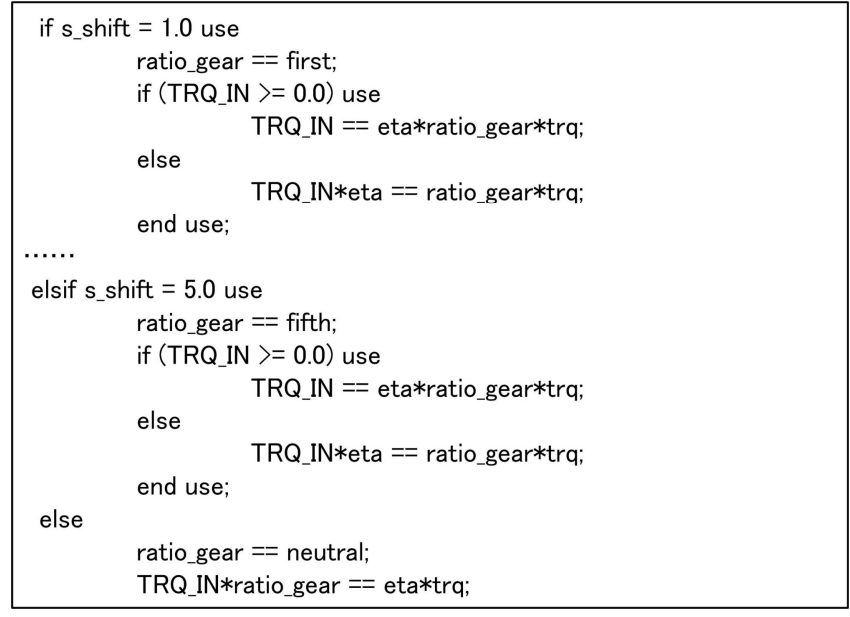

Fig. 8. Gear Box Model

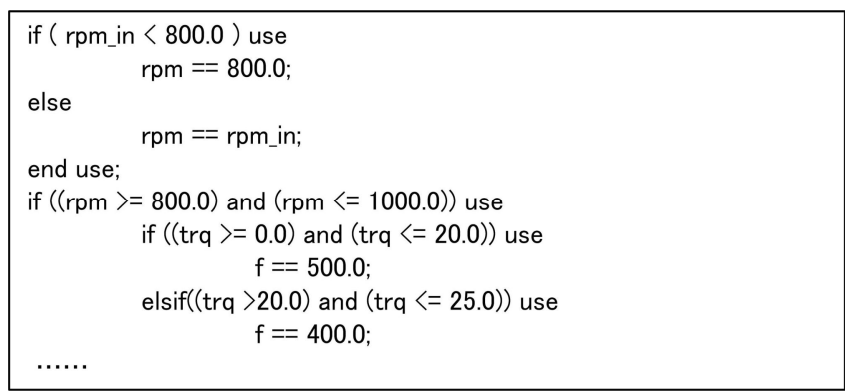

Fig. 9. Engine Map Model

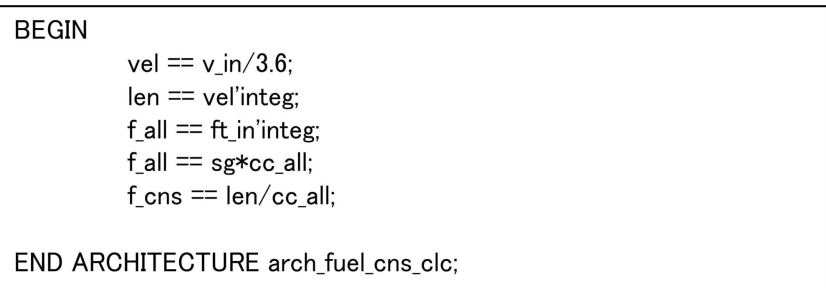

Fig. 10. Fuel Consumption Calculation Model

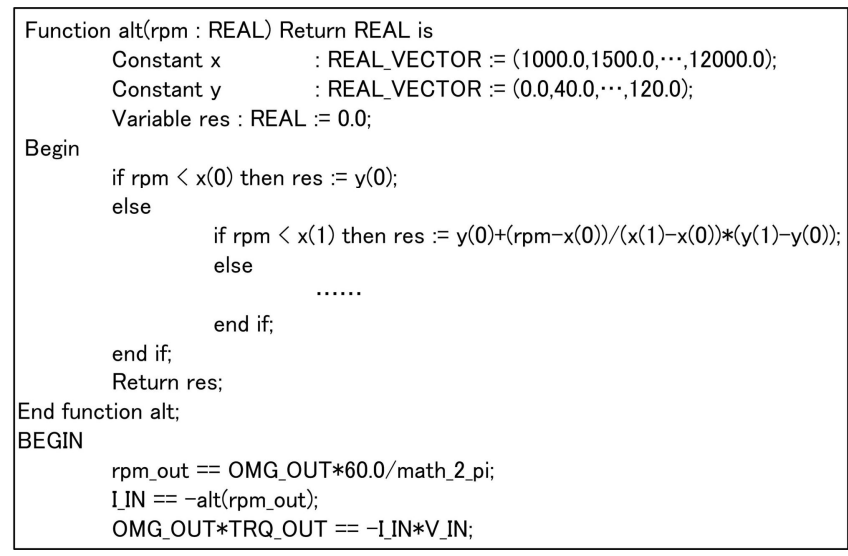

Fig. 11. Alternator Model 


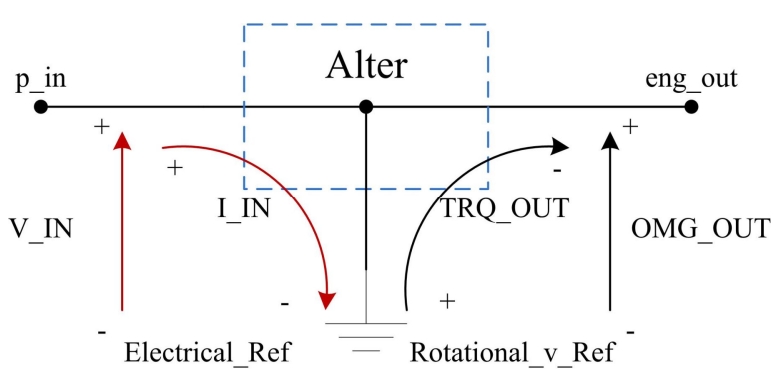

Fig. 12. Alternator Model

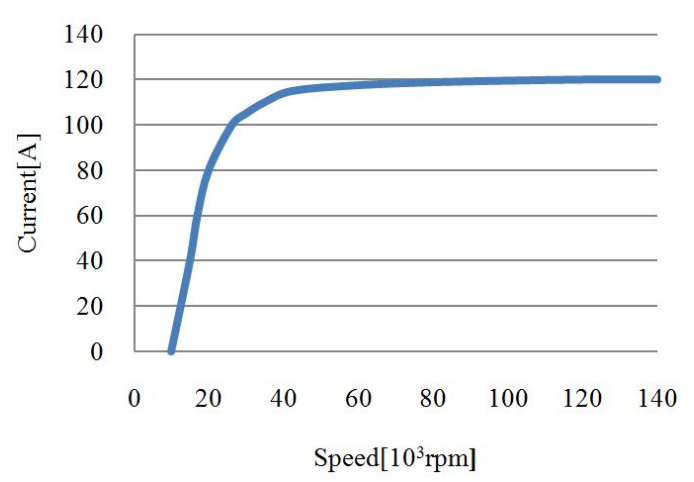

Fig. 13. The current - speed characteristic

\section{(8) Battery Modeling}

The lead-acid storage battery is widely used in today's vehicles. The chemical reaction of the battery electrodes causes the acidic concentration to be lower near the electrodes during the discharge state. The diffusion of acidic molecules between the upper and lower concentration regions was modeled using the equivalent circuit shown in Fig. 14, by using diffusion resistance, in addition to a slow- and fast-charging and discharging capacitor [8]. Part of the model description by VHDL-AMS using the equivalent circuit from Fig. 14 is shown in Fig. 15.

\section{(9) Load Modeling}

For this research, the load was modeled as ideal resistance. For the electrical load, $R_{1}$ is $0.9 \Omega$ and $R_{2}$ is $7 \Omega$. $R_{1}$ is equivalent to using the lights and air-conditioning, and $R_{2}$ simulates the hazard lights [9].

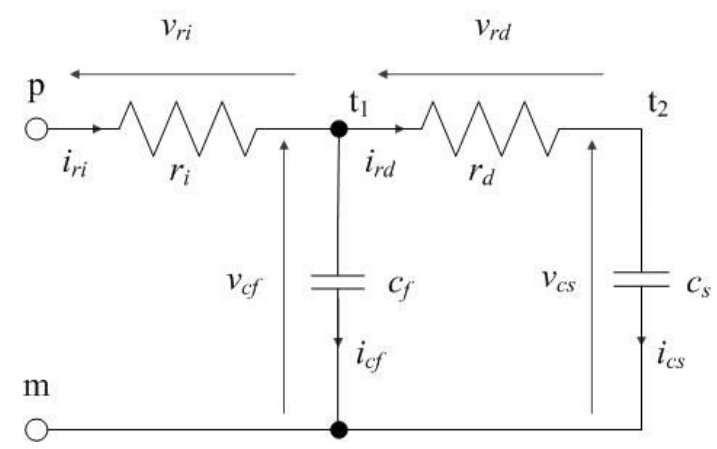

Fig. 14. Equivalent Circuit of Battery

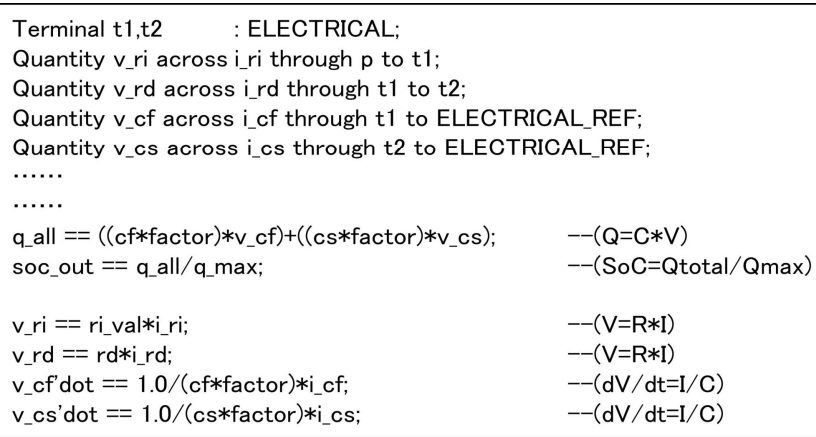

Fig. 15. Battery Model

\subsection{Mode Model}

Mode model is used to input the vehicle running speed into the simulation model. In the mode model, the Japanese 10-15 mode speed profile is used as shown Fig. 16. The Japanese 10-15 mode is the measurement of fuel consumption on the condition stipulated by the Ministry of Land Infrastructure Transport and Tourism. The fuel consumption is measured on not the actual load but chassis dynamometer at the following condition.

a) Vehicle after braking-in over $3000 \mathrm{~km}$ distance

b) Fully warm-up condition (after 15 minutes warmup operation at $60 \mathrm{~km} / \mathrm{h}$ )

c) The vehicle weight including 2 passengers $(110 \mathrm{~kg})$.

d) Turn off the air conditioning and vehicle electrical equipment

e) The test room temperature $25 \mathrm{deg}$. \pm 5 deg., relative humidity is kept within the range of $75 \%$ from $30 \%$

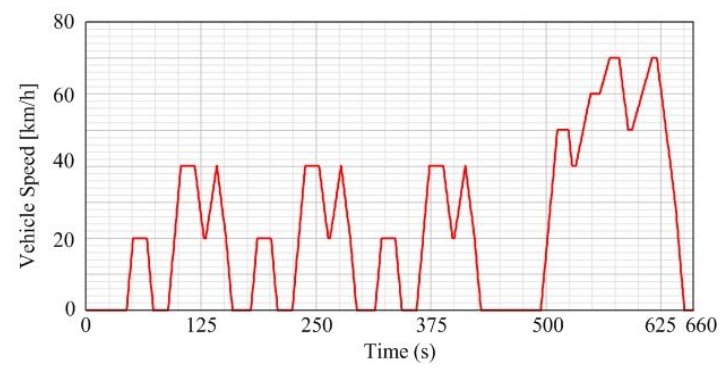

Fig. 16. Vehicle Speed (10-15mode)

\section{Analysis Results}

As a vehicle simulation model, four-cylinder engine and five speed manual transmissions vehicle was modeled. The representative parameters are listed on the table 2 from target vehicle catalog and specifications. The Simplorer by ANSYS, Inc. [8] was used as the multi-domain simulator supported the use of VHDL-AMS. 
Table 2. Target Vehicle Specifications

\begin{tabular}{|l|l|c|}
\hline \multirow{4}{*}{ Vehicle } & \multicolumn{2}{|c|}{ Parameter } \\
\cline { 2 - 3 } & Name & Value \\
\hline \multirow{4}{*}{ Tire } & Mass & $1110 \mathrm{~kg}$ \\
\cline { 2 - 3 } & Front projection area & $1.83 \mathrm{~m}^{2}$ \\
\cline { 2 - 3 } & Air coefficient & 0.29 \\
\cline { 2 - 3 } Trans & Air density & $0.125 \mathrm{kgs}^{2} / \mathrm{m}^{4}$ \\
\hline \multirow{5}{*}{ mission } & Radius & $0.32 \mathrm{~m}$ \\
\cline { 2 - 3 } & Rolling coefficient & 0.013 \\
\hline & $1^{\text {st }}$ gear ratio & 3.545 \\
\cline { 2 - 3 } & $2^{\text {nd }}$ gear ratio & 1.904 \\
\cline { 2 - 3 } & $3^{\text {rd }}$ gear ratio & 1.233 \\
\cline { 2 - 3 } & $4^{\text {th }}$ gear ratio & 0.885 \\
\cline { 2 - 3 } & $5^{\text {th }}$ gear ratio & 0.725 \\
\cline { 2 - 3 } & Final reduction gear ratio & 4.312 \\
\cline { 2 - 3 } Battery & Efficiency & $0.95 \%$ \\
\hline Alternator & Figure 12 & 0.01 \\
\hline \multirow{5}{*}{} & Resistance $r_{i}$ & 0.04 \\
\cline { 2 - 3 } & Resistance $r_{d}$ & 60 \\
\cline { 2 - 3 } & Capacitance $c_{f}$ & 20000 \\
\cline { 2 - 3 } & Capacitance $c_{s}$ & \\
\hline
\end{tabular}

At first, it is reported that the results of fuel consumption model does not take into account the slope and electrical equipment. This condition is quite similar to the 10-15 mode. When the vehicle running speed varied from $20 \mathrm{~km} / \mathrm{h}$ to $0 \mathrm{~km} / \mathrm{h}$, the clutch is disengaged at $10 \mathrm{~km} / \mathrm{h}$. Similarly, from $40 \mathrm{~km} / \mathrm{h}$ to $0 \mathrm{~km} / \mathrm{h}$ : at $20 \mathrm{~km} / \mathrm{h}$, from $70 \mathrm{~km} / \mathrm{h}$ to $0 \mathrm{~km} / \mathrm{h}$ : at $30 \mathrm{~km} / \mathrm{h}$. When the vehicle running speed is $0 \mathrm{~km} / \mathrm{h}$ or the clutch is disengaged, the engine rotational speed is $800 \mathrm{r} / \mathrm{min}$. The fuel consumption on decelerating condition and idling condition are $0.0 \mathrm{~g} / \mathrm{s}$ and $0.1 \mathrm{~g} / \mathrm{s}$, respectively. The resulting fuel consumption was $17.8 \mathrm{~km} / \mathrm{L}$ as shown in Fig. 17. As the resulting value is almost similar to the catalog fuel consumption of $17.2 \mathrm{~km} / \mathrm{L}$, this system model is useful for fuel consumption simulation.

Figure 18 shows the fuel consumption result when we consider the influence of the electrical equipment. The fuel consumption here was $16.4 \mathrm{~km} / \mathrm{L}$ which is evidently a decrease in $7.87 \%$. Fuel consumption for the electrical equipment in current automobiles has been 5 to $10 \%$ of the total fuel consumption. Thus, the result was befitting in that range. The alternator current is also shown in Fig. 19.

Finally, Fig. 20 and 21 illustrates the results of fuel consumption in consideration of slope. It shows the inputted slope in the vehicle running resistance model in Fig. 19. In case of the required torque for a positive slope climbing in the interval is unobtainable, each shift position could be shifted down so that the required torque could be obtain. As the results, the fuel consumption was $14.7 \mathrm{~km} / \mathrm{L}$. It indicates $10.4 \%$ deterioration in comparison with the electrical equipment.

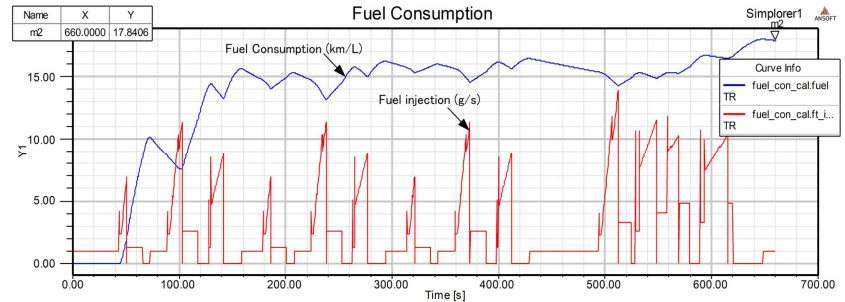

Fig. 17. Fuel Consumption (no load and no slope)

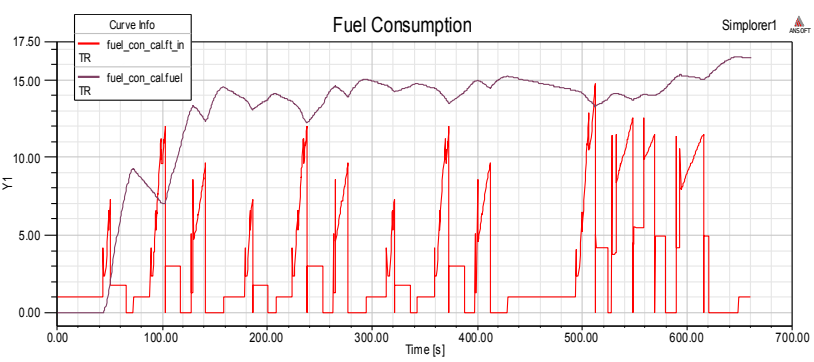

Fig. 18. Fuel Consumption (Add load)

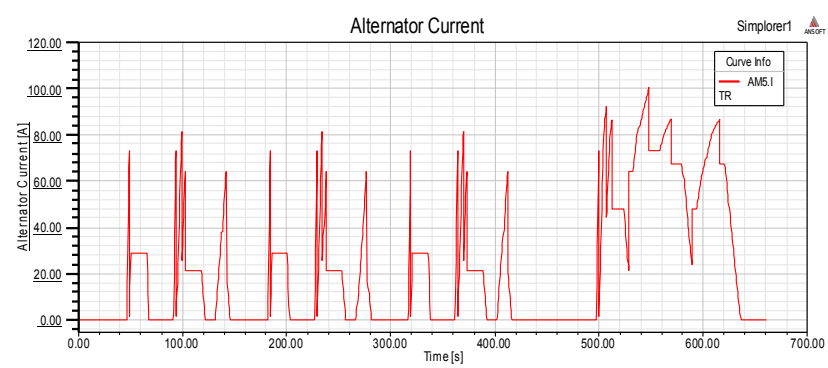

Fig. 19. Alternator current

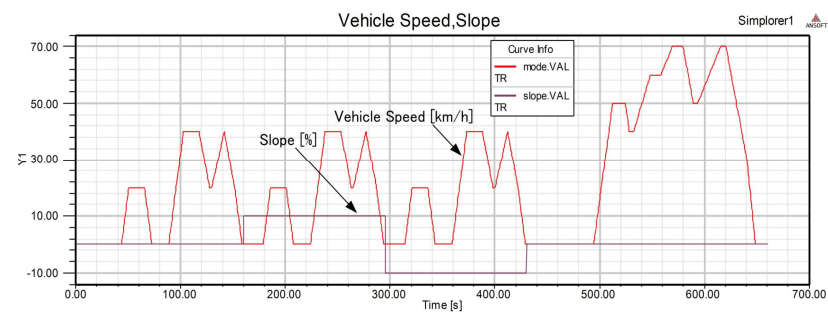

Fig. 20. Vehicle Speed And Slope

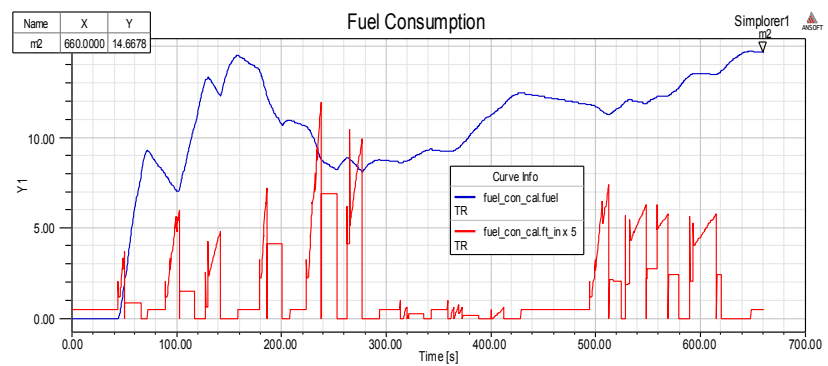

Fig. 21. Fuel Consumption (Add load and slope) 


\section{Conclusion}

This paper described the modeling method of the vehicle system and the fuel consumption calculation using standardized circuit description language VHDL-AMS. The modeling results showed that VHDL-AMS is useful for conducting a vehicle system simulation. As the results, this research can be applied to the energy management investigation using vehicle system for carbon dioxide reduction. In addition, on the design stage, our simulation method enables the development cost and time to be reduced.

\section{References}

[1] IEEJ, Investigation Committee on Management of Automotive Electric Power Supply Systems : "Management Technology of Automotive Electric Power Supply Systems “No.1121(2008)

[2] David Wenzhong Gao, Chris Mi, Ali Emadi,: "Modeling and Simulation of Electric and Hybrid Vehicles", Proceedings of the IEEE, Vol. 95, No.4, (2007)

[3] IEEE:"IEEE Standard VHDL Analog and Mixed-Signal Extensions", IEEE Std 1076.1-2007, ISBN: 0-7381-5627-2 (2007)

[4] K. Tsuji, M. Enomoto, T. Abe : "Analysis of Alternator Regeneration using VHDL-AMS vehicle system simulation", the 34th Annual Conference of the IEEE Industrial Electronics Society, HF-005843, pp.2788-2793 (2008)

[5] S. Yamamoto, T. Abe, T. Higuchi, K. Tsuji : "A Multi-level Simulation using VHDL-AMS and Coupled Analysis for an Alternator Regeneration System in a Vehicle", Proc. of the 13th European Conference on Power Electronics and Applications, No.0565, pp.1-7(CD-ROM), (2009)

[6] K. Tsuji, S. Yamamoto, T. Abe, T. Higuchi, M. Enomoto : "An Energy Analysis for Alternator Regeneration System Using VHDL-AMS Multi Domain Simulation", Proc. of International Conference on Electrical Machines and Systems, No.LS6A-2, pp.1-6, (2009)

[7] K. Tsuji, Y. Kido, T. Abe : "A Study of Vehicle Energy Analysis during Warming up Process using VHDL-AMS Multi-Domain Simulation", Proc. Of International Power Electronics Conference, No.24G-2, pp.2935-2940 (2010)

[8] Ansoft Corporation : "SIMPLORER VHDL-AMS TUTORIAL" (2003)

[9] N. Nagashima, R. Ochiai, G. Fujita, T. Fukada : "Development of Simulation Model for Vehicle's Electrical Power System", 2008 National Convention Record IEE Japan IAS, Vol.2, No.59, pp.533-534 (2008)

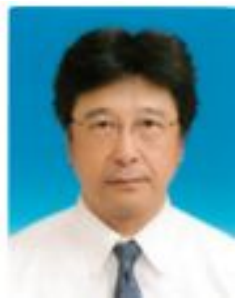

Takashi Abe received Ph.D. degree from Nagasaki University in 2005 . He is currently an Associate Professor of Nagasaki University. His research interests are electrical machine drive, power electronics and Vehicle simulation. He is a member of the IEEE, the IEE of Japan, SAE of Japan and Japanese Society for MBE.

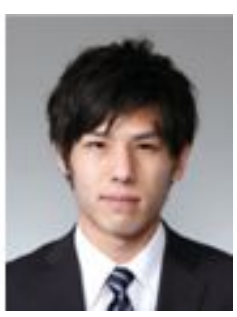

Shiko Takakura received Bachelor's degree from Nagasaki University in 2012. He is currently a Master course student of Nagasaki University. His research interests are Vehicle simulation. He is a member of the IEE of Japan.

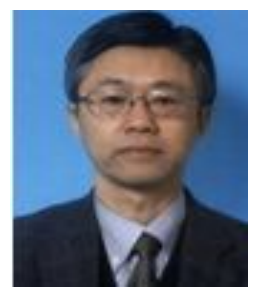

Tsuyoshi Higuchi received Ph.D. degree from Kyushu University, Japan in 1983 . He is currently a Professor of Nagasaki University, Japan. His research interests are analysis, design and control of linear and rotary machines such as switched reluctance motors and permanent magnet motors. He is a member of IEEE, IEE of Japan. 